\title{
ПРИЛАДИ
}

УДК 004.89

DOI https://doi.org/10.32838/2663-5941/2020.4/03

Черепанська І.Ю.

Поліський національний університет

Безвесільна О.М.

Національний технічний університет України

«Київський політехнічний інститут імені Ігоря Сікорського»

Сазонов А.Ю.

Національний технічний університет України

«Київський політехнічний інститут імені Ігоря Сікорського»

Бродський Ю.Б.

Поліський національний університет

Прядко В.А.

Поліський національний університет

\section{МАТЕМАТИЧНА МОДЕЛЬ ПОХИБКИ ПРЕЦИЗІЙНОЇ ПРИЛАДОВОЇ СИСТЕМИ ВИМІРЮВАННЯ КУТІВ}

У статті представлена повна математична модель похибки прещизійної приладової системи вимірювання кутів (ППСВК), щзо отримана шляхом вдосконалення відомої базової математичної моделі похибки гоніометричної системи ГС ЛЛ, яка є прототипом ППСВК. Повна математична модель похибки ППСВК, на відміну від відомих, враховує нестабільності швидкості обертання Землі навколо своєї осі, а також флуктуачійні напруги, щзо з'являються в прочесі функиіонування фоточутливої КМОП-матрииі як складника ППСВК та зумовлюються наявністю теплового і дробового ефектів, що виникають в ї̈ структурних елементах. Нестабільність швидкості обертання Землі навколо своєї осі, а також тепловий та дробовий ефекти, що виникають у структурних елементах КМОП-матриці, є несприятливими факторами, які мають місие як у лабораторних, так і у виробничих умовах, наприклад, прецизійного приладо- та машинобудування, і суттєво зменшують точність. Крім изього, необхідність побудови повної математичної моделі похибки ППСВК зумовлюється синергетичною інтеграчією в ї̈ структурі нових введених авторами технічних засобів автоматизації - фоточутливої КМОП-матриці та штучних нейронних мереж (у разі реалізаиії останніх у вигляді нейропроцесорів), а також використанням як прецизійного датчика кута кільчевого лазеру, що є чутливим до нестабільності швидкості обертання Землі. Пропонована повна математична модель похибки ППСВК використовується для обчислення величин похибок гоніометричних вимірювань із подальшою алгоритмічною корекцією результатів вимірювання під час функціонування ППСВК. Перевагами пропонованої повної математичної моделі похибки ППСВК є те, щэо вона системно враховує особливості складників ППСВК і дає змогу проводити подальшу корекиію результатів вимірювання в динамічному режимі безпосередньо в прочесі експлуатації ППСВК без застосування спеціалізованого лабораторного обладнання. Практична реалізація вказаного здійснюється в спеціалізованому програмному додатку ПК, що є складником ППСВК.

Ключові слова: похибка, гоніометрична система, алгоритмічна корекиія, систематична похибка, випадкова похибка, флуктуаиійні напруги, дробовий ефект, тепловий ефект.

Постановка проблеми. У процесі розробки сучасних високоточних гоніометричних систем, що використовуються для проведення різноманітних вимірювань величин плоских кутів у багатьох галузях науки і техніки, особлива увага приділяється підвищенню їх точності. Одним із перспективних i актуальних шляхів підвищення точності різних гоніометричних систем, у тому числі відомої прецизійної приладової системи вимірювання кутів (ППСВК) [1], нині $є$ алгоритмічна компенсація 
похибок, що передбачає розробку відповідних математичних моделей та їх використання для корекції результатів вимірювання. Це дає змогу здійснювати корекцію результатів вимірювання, без застосування спеціалізованого лабораторного обладнання, безпосередньо під час проведення експерименту та в процесі експлуатації ППСВК. Тому актуальною задачею $є$ отримання математичної моделі похибки, що відповідає процесам, які відбуваються під час функціонування ППСВК.

Аналіз останніх досліджень і публікацій показав, що алгоритмічна корекція результатів вимірювання успішно застосовується для підвищення точності вимірювань. Теоретичні основи та досвід застосування алгоритмів корекції описано в працях вітчизняних та зарубіжних науковців [2-10]. Зокрема, відома робота «Алгоритмічні методи високоточного визначення лінійних прискорень» [2], в якій автор розглядає алгоритмічні методи корекції при високоточних визначеннях лінійних прискорень у режимі реального часу. Основою цих методів $\epsilon$ ідентифікація вектора стану чутливого елементу у вимірювачах прискорень, які використовуються в інерціальних та гравіметричних системах. У роботі С.В. Суханова [3] розглядаються алгоритми компенсації похибок вихідного сигналу лазерного гіроскопа. Г.Н. Ковшов і Л.І. Живцова [4] наводять математичну модель інструментальних похибок інклінометра на основі блоку триосьового акселерометричного перетворювача для інклінометричних систем контролю. Вказана математична модель застосовується в процесі корекції результатів вимірювання, що дає змогу підвищити точність. У роботі [5] описано нейромережевий алгоритм підвищення точності гоніометричних вимірювань та корекції вихідного сигналу. У роботі «Алгоритмические методы повышения точности измерений на основе обратных интерполяционных моделей» [6] розглядаються методи підвищення точності вимірювань на основі зворотних математичних моделей вимірювального каналу. А.Д. Дорожкін, О.А. Джусь [7] розглядають основні методи підвищення точності навігаційного комплексу в режимі корекції. Встановлено, що найбільш актуальними $\epsilon$ структурно-алгоритмічні методи підвищення точності. Вказується, що розробка та вдосконалення алгоритмічного забезпечення дають змогу більш гнучко та ефективно використовувати як нові, так і відомі системи та датчики вимірювальних систем. У роботі П.А. Павлова [8] показано, що в разі використання алгоритму компенсації узагальненого зсуву нуля зменшується вплив нестабільності швидкості обертання кільцевого лазера на систематичну та випадкову складові частини похибки вимірювання лазерним динамічним гоніометром. У роботі Т.Ю. Цибізової та Д.Т. Нгуен [9] розглянута схема алгоритмічної компенсації похибок навігаційних систем у вихідному сигналі 3 використанням еволюційних алгоритмів, зокрема генетичного алгоритму. Показано роботоспроможність генетичного алгоритму для побудови прогнозних моделей похибок інерціальної навігаційної системи в схемі корекції навігаційної інформації датчиків. У роботі «Алгоритмічна корекція результатів вимірювання прецизійної приладової гоніометричної системи» [10] наводиться алгоритмічний метод корекції результатів вимірювання величин плоских кутів прецизійною приладовою гоніометричною системою. Показано, що алгоритмічна корекція результатів вимірювання може проводитись без застосування спеціалізованого лабораторного обладнання безпосередньо в процесі експлуатації прецизійної приладової гоніометричної системи під час експерименту.

Необхідно вказати, що в одних роботах [2-4; 6-9] не висвітлюються питання корекції результатів гоніометричних вимірювань, в інших роботах $[5 ; 10]$ не враховуються завади у випадку роботи ППСВК у несприятливих та нестаціонарних умовах, зокрема не враховується нестабільність швидкості обертання Землі навколо своєї осі, а також флуктуаційні напруги, які виникають під час функціонування фоточутливої КМОП-матриці як складника ППСВК та зумовлюються наявністю теплового і дробового ефектів, що виникають в їі структурних елементах.

Враховуючи, що ППСВК призначена для вимірювання плоских кутів, пірамідальності призм та інших об'єктів високоточного виробництва, а також може застосовуватись при попередній виставці навігаційних чутливих елементів, визначення показника заломлення оптичного скла, вимоги до іiі точності та точності результатів вимірювання $\epsilon$ надзвичайно високими. Зокрема, похибка вимірювання ППСВК не має перевищувати $0,12 "$, що відповідає похибці сучасних гоніометричних систем кращих світових зразків. При цьому необхідно враховувати, що гоніометричні вимірювання ППСВК, окрім лабораторних умов, проводяться також у нестаціонарних виробничих умовах, наприклад, автоматизованих приладота машинобудування тощо. Відомо, що нестаціонарні виробничі умови супроводжуються виникненням низки завад, які додаються до вихідного вимірювального сигналу ППСВК. Тому необхідно враховувати ці особливості в процесі розробки 
математичної моделі похибок, що є основою алгоритмів корекції результатів вимірювання.

Постановка завдання. Мета статті - розробити повну математичну модель похибки ППСВК, що враховує завади, які додаються до вихідного вимірювального сигналу і зумовлюються особливостями складників ППСВК.

Виклад основного матеріалу дослідження. Необхідність побудови повної математичної моделі похибки ППСВК зумовлюється синергетичною інтеграцією в її структуру, що побудована на базі відомої прецизійної гоніометричної системи ГС1Л КП СПБ «Арсенал», нових технічних засобів - фоточутливої КМОП-матриці та штучних нейронних мереж (у разіреалізації останніх у вигляді нейропроцесорів), а також використанням як чутливого елементу кільцевого лазера (КЛ), що є прецизійним датчиком кута, чутливим до нестабільності швидкості обертання Землі. Повна математична модель похибки використовується для обчислення величини похибки 3 подальшою алгоритмічною корекцією результатів вимірювання під час функціонування ППСВК.

Пропонована повна математична модель похибки ППСВК розроблена шляхом вдосконалення відомої базової математичної моделі похибки автоматизованого прецизійного пристрою для вимірювання кутів, побудованого на базі гоніометричної системи ГС1Л, що є прототипом ППСВК. Відома базова математична модель похибки автоматизованого прецизійного пристрою для вимірювання кутів наведена у праці О.М. Безвесільної [11].

Повна математична модель похибки ППСВК системно враховує особливості ії складників та має такий вид:

$$
\begin{aligned}
& \Delta \phi=\mathrm{f}\left(\Delta \phi_{I} ; \Delta \phi_{M} ; \Delta \phi_{S}\right)= \\
& =\left(2 \pi \frac{\int_{t_{1}}^{t_{\phi}}\left[K(t) \omega_{\Sigma}(t) \cos \alpha(t)+\frac{K_{-1}(t)}{\omega_{\Sigma}(t) \cos \alpha(t)}+\omega_{0}(t)\right] d t+N_{q 1}}{\int_{t_{1}}^{t_{2 \pi}}\left[K(t) \omega_{\Sigma}(t) \cos \alpha(t)+\frac{K_{-1}(t)}{\omega_{\Sigma}(t) \cos \alpha(t)}+\omega_{0}(t)\right] d t+N_{q 2}}+\Delta \phi_{c a l}+\Delta \phi_{\text {cmos }}\right)-\phi, \\
& \delta_{\text {cmos }}=\delta^{d r}{ }_{\text {cmos }}+\delta_{\text {cmos }}^{t},
\end{aligned}
$$

де $\Delta \varphi$ - похибка вимірювання кутів ППСВК;

$\Delta \varphi_{I}-$ інструментальна похибка;

$\Delta \phi_{M}$ - методична похибка повірки гоніометра;

$\Delta \varphi_{S}-$ суб'єктивна похибка оператора;

$t_{1}, t_{\phi}, t_{2 \pi}$ - моменти часу початку вимірювання, повороту на вимірюваний кут $\varphi$, та кут $2 \pi$ відповідно, що зафіксовані автоколіматором;

$K(t)$ - масштабний коефіцієнт КЛ, що використовується як датчик кута;

$\omega_{\Sigma}$ - кутова швидкість, що впливає на гоніометр, та зумовлюється кутовими швидкостями обертової платформи $(\bar{\omega}(t))$, Землі $\left(\overline{\omega_{3}}\right)$ і основи обертової платформи відносно Землі $\left(\overline{\omega_{b a s}}(t)\right)$;

$\alpha(t)$ - кут між віссю обертання обертового пристрою і віссю чутливості гоніометра;

$K_{-1}(t), \omega_{0}(t)$ - нелінійність і зсув нуля вихідної характеристики КЛ відповідно;

$N_{q 1}, N_{q 2}$ - шум і дискретність квантування сигналу;

$\Delta \phi_{c a l}$ - похибка обчислень значень вимірюваного кута в ЕOM;

$\Delta \phi_{\text {cmos }}$ - похибка фоточутливої КМОП-матриці, зумовлена фотонним та тепловим шумом;

$\phi-$ дійсне значення вимірюваного кута.
У процесі функціонування ППСВК на прецизійний датчик кута (зокрема, на величину дрейфу нуля його вихідної характеристики) справляє вплив нестабільність швидкості обертання Землі навколо своєї осі. Причому цей вплив має переважно випадковий характер. У ППСВК як прецизійний датчик кута використовується КЛ 3.970.029, розроблений КП СПБ «Арсенал» спільно з кафедрою приладобудування Національного технічного університету України «Київський політехнічний інститут імені Ігоря Сікорського».

У процесі функціонування КЛ спостерігається нестабільність його параметрів, зокрема відбувається дрейф нуля $\omega_{0}$ вихідної характеристики та дрейф $\mathrm{K}_{-1}$ масштабного коефіцієнта. Структурна схема флуктуаційних процесів та похибок КЛ наведена на рис. 1.

Розрахункове значення масштабного коефіцієнта становить $K=1,03 \cdot 10^{-5}$ при довжині сторони резонатора, виконаного у вигляді рівностороннього трикутника 22,7 см, та довжині хвилі $\lambda=0,6328$ мкм. Проте під час функціонування КЛ відбувається дрейф масштабного коефіцієнта, що призводить то зміни його точності. В ідеальному випадку масштабний коефіцієнт $K$ змінюється лінійно, але в реальних умовах на лінійні зміни накладаються такі флуктуації: 


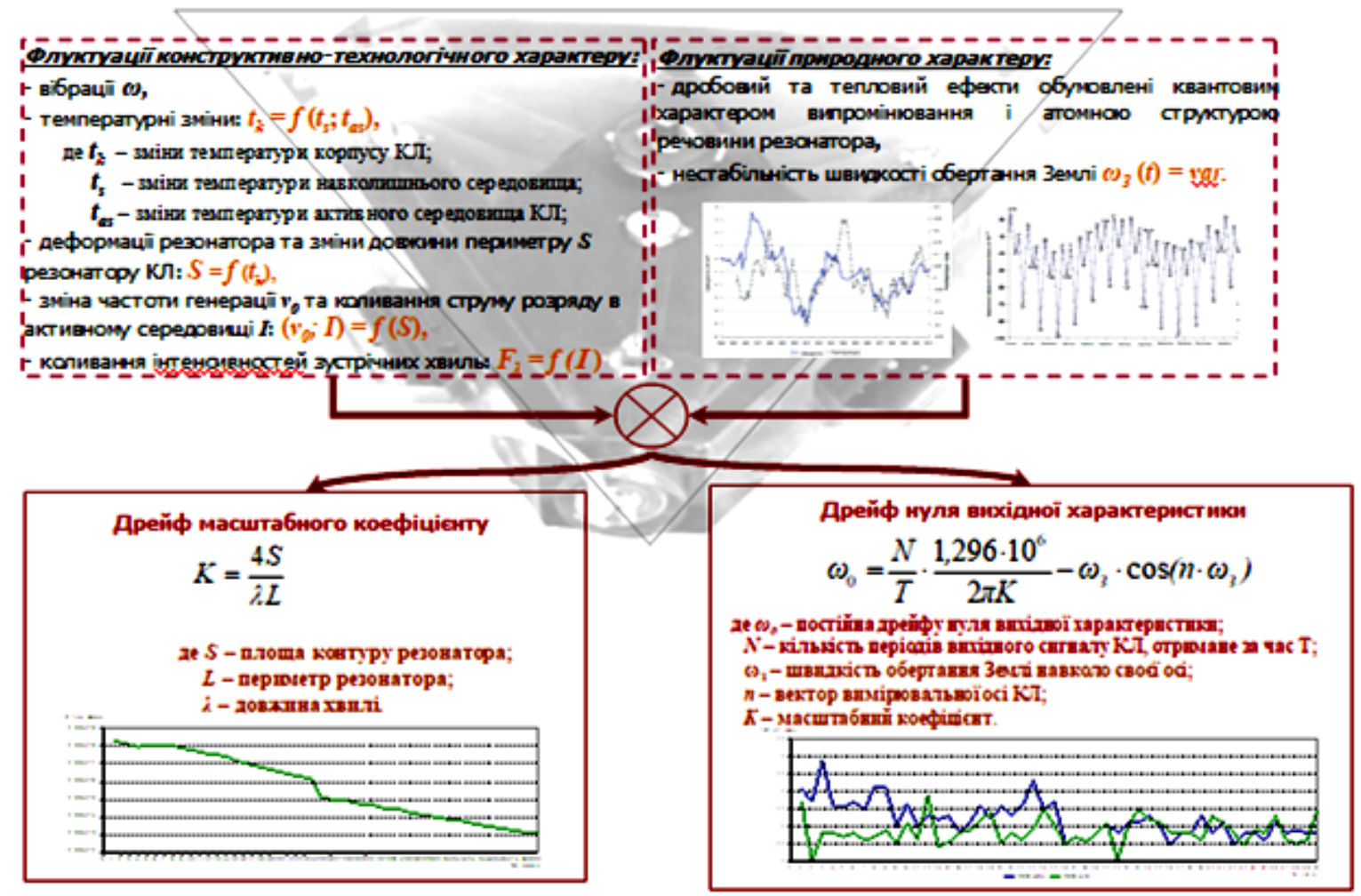

Рис. 1. Структурна схема флуктуаційних процесів та похибок КЛ

- конструктивно-технологічні флуктуації, що мають систематичний характер та усуваються відповідними конструктивними доопрацюваннями;

- флуктуації, зумовлені фізичною природою процесів та явищ, що виникають при функціонуванні КЛ, які мають випадковий характер.

До останніх належить нестабільність швидкості обертання Землі $\omega_{3}$ навколо своєї осі, яка, як відомо $з$ багатьох досліджень науковців, $є$ нестабільною $\omega_{3} \neq$ const та змінюється стрибкоподібно через вплив різних флуктуацій, викликаних планетарними силами - дрейфом магнітних полюсів, теплового градієнта, нестабільністю осі обертання. Кутова швидкість обертання Землі змінюється впродовж доби протягом всього року. Відома теорія дає змогу обчислювати коливання швидкості обертання Землі на будь-який інтервал часу.

Взаємозв'язок між швидкістю обертання Землі $\omega_{3}$ та параметрами КЛ (дрейфом масштабного коефіцієнту $K$ та нуля $\omega_{0}$ ) можна показати взаємозв'язаними виразами:

$$
\begin{gathered}
\omega_{0}=\frac{N}{T} \cdot \frac{1,296 \cdot 10^{6}}{2 \pi K}-\omega_{3} \cdot \cos \left(n \cdot \omega_{3}\right) \Rightarrow \\
\Rightarrow K=\frac{N}{T\left(\omega_{0}+\omega_{3} \cdot \cos \left(n \cdot \omega_{3}\right)\right)} \cdot \frac{1,296 \cdot 10^{6}}{2 \pi K}
\end{gathered}
$$

де $\omega_{0}-$ постійна дрейфу нуля вихідної характеристики;
$N$ - кількість періодів вихідного сигналу КЛ, отримана під час додавання за час $T$, $N=\frac{1}{2 \pi} \int_{0}^{T} \Delta \omega d t$

$\omega_{3}$ - швидкість обертання Землі навколо своєї осі; $n$ - вектор вимірювальної осі КЛ;

$K$ - масштабний коефіцієнт, що визначається за відомою формулою $K=\frac{4 S}{\lambda L}=\frac{2 \pi R_{e \phi}}{\lambda / 2}$, де $S$ - площа контуру резонатора; $L$ - периметр резонатора; $\lambda$ - довжина хвилі; $R_{e q}$ - довжина кола, вписаного в оптичний контур резонатора КЛ, $R_{e \phi}=\frac{2 S}{L} ; \lambda / 2-$ відстань між вузлами стоячої хвилі.

Iз виразу (2) видно, що за умови $\omega_{3} \neq$ const показники $K$ та $\omega_{0} \epsilon$ нестабільними величинами $K \neq$ const,$\omega_{0} \neq$ const:

$$
\omega_{3} \neq \text { const } \Rightarrow\left\{\begin{array}{l}
\omega_{0}=\text { var } \\
K=\text { var }
\end{array}\right.
$$

Випадковий характер зміншвидкостіобертання Землі, які частково визначають дрейф нуля $\omega_{0}$ та масштабного коефіцієнту $K$ КЛ пропонованої ППСВК, вказує на випадковий характер цієї складової частини інструментальної похибки $\Delta \phi_{I}$ (див. вираз (1)). 
Фоточутлива КМОП-матриця, що використовується у ППСВК як аналізатор сигналу від автоколіматора в діапазоні випромінювань від 400 нм до 1000 мкм, має похибку $\delta_{\text {cmos }}$, зумовлену шумами, що мають випадковий характер. Відомим параметром, яким описують порівняну величину шуму в сигналі, $є$ коефіцієнт шуму, що визначається як відношення величини корисного сигналу $S$ до шуму $F$, вимірюється в децибелах та має логарифмічний масштаб величини:

$$
S / \mathrm{F}=10 \log _{10} F .
$$

У фоточутливій КМОП-матриці виникають шуми, найсуттєвішими $з$ яких для ППСВК є фотонний (дробовий) шум та шум теплового сигналу.

Фотонний (дробовий) шум виникає внаслідок дискретності природи світлового випромінювання. Він проявляється як випадкові флуктуації напруг $U_{d r}$ та струмів у фоточутливих елементах (пікселях) матриці, що визначають похибку $\delta_{c m o s}^{d r}$ від дробового ефекту або фотонного шуму:

$$
\delta_{c m o s}^{d r}=f\left(U_{d r}\right),
$$

де $U_{d r}$ - флуктуаційні напруги, що виникають через дробовий ефект, середне квадратичне значення яких визначається за виразом $U_{d r}^{2}=2 q i R^{2} \Delta f$, де $R$ - опір, Ом; $\Delta f$ - інтервал (смуга) частот, в межах якого реєструється сила фотоструму, Гц; $q$ - заряд електрона, $q=1,6 \cdot 10^{-19} \mathrm{Kл} ; i-$ величина струму, А.

Переміщення кожного носія заряду (електрона) КМОП-матриці супроводжується стрибком напруги в електричному колі. При швидкості зчитування зарядів до 500 елементів в сек на пікселі матриці потрапляє різна кількість фотонів, яка підпорядковується розподіленню Пуассона.

Шум темнового сигналу (тепловий шум) виникає внаслідок термоелектронної емісії. Тепловий шум виникає тільки в провідниках з активним опором (у провідниках із реактивним опором - ємностях та індуктивностях тепловий шум не виникає) та пов'язаний із хаотичним рухом рухомих носіїв заряду. Внаслідок цього з'являються флуктуації напруги $U_{t}$, що визначають величину похибки $\delta_{\text {cmos }}^{t}$ від теплового шуму:

$$
\delta_{c m o s}^{t}=f\left(U_{t}\right),
$$

де $U_{t}$ - флуктуаційна напруга при тепловому русі зарядів, середнє квадратичне значення якої визначається за відомою формулою $U^{2}{ }_{t}=4 k T R \Delta f$, де $k$ - постійна Больцмана, $k=1,38 \cdot 10^{-23}$ Дж/К; $T$ - абсолютна температура $T, \mathrm{~K} ; R$ - опір, Ом; $\Delta f$ - інтервал (смуга) частот, Гц.
Відомо, що тепловий шум, який визначається флуктуаційною напругою $U_{t}$ в постійній смузі частот при $\Delta f=$ const має лінійну залежність від абсолютної температури $T$. Цей факт дає змогу зменшувати складник $\delta_{c m o s}^{t}$ похибки $\delta_{\text {cmos }}$, КМОПматриці від теплового шуму відповідно до наступного формалізованого виразу:

$$
T \rightarrow 0 \Rightarrow U_{t} \rightarrow 0: U_{t}=f(T),
$$

Опорною величиною абсолютної температури $T$ щодо джерела теплового шуму у КМОП-матриці $\epsilon$ значення $290 \mathrm{~K}$ або $17^{\circ} \mathrm{C}$. Тому при експлуатації пропонованої ППСВК для зменшення $U_{t}$ температура $T$ має бути близькою до $17^{\circ} \mathrm{C}$.

Величина корисного сигналу КМОП-матриці визначається за формулою:

$$
S=\frac{U_{S}^{2}}{U_{d r}^{2}+U_{t}^{2}},
$$

де $U_{S}^{2}-$ величина напруги на виході КМОПматриці.

Таким чином, величина похибки $\delta_{\text {cmos}}$, що вноситься КМОП-матрицею, має дві складові частини: похибку від дробового ефекту або фотонного шуму $\delta_{c m o s}^{d r}$ та похибку від теплового шуму $\delta_{\text {cmos }}^{t}$ :

$$
\delta_{\text {cmos }}=\delta^{d r}{ }_{\text {cmos }}+\delta_{\text {cmos }}^{t} .
$$

Фізична природа складників похибки $\delta_{c m o s}$ вказує на їі випадковий характер.

Таким чином, складниками інструментальної похибки $\Delta \varphi_{I}$ (див. вираз (1)) ППСВК є систематичний та випадковий складник. Систематичний складник інструментальної похибки $\Delta \varphi_{I}$ порівняно легко усувається в результаті використання при побудові ППСВК складників, що мають стабільні параметри (використовується матриця 3 розмірністю пікселів 1,0 × 1,0 мкм, наприклад, OV16880 або OV20880 виробництва OmniVision (США), завдяки високій роздільній здатності елементів матриць та ортогональній структурі КМОП-матриці загалом, досягається похибка вимірювання 0,1". Також як прецизійний датчик кута використовується КЛ 3.970.029 виробництва КП СПБ «Арсенал» (Україна), що має високу точність та зумовлює похибку не більше $0,1 "$.

Випадковий скланик інструментальної похибки $\Delta \varphi_{I}$ (див. вираз (1)) частково визначається похибками $\delta_{c m o s}^{d r}$ та $\delta_{\text {cmos }}^{t}$, що становлять похибку $\Delta \phi_{\text {cmos }}$ КМОП-матриці та виникають від дробового ефекту або фотонного шуму відповідно, а також похибкою, що вноситься нестабільністю швидкості обертання Землі навколо своє осі 
$\left(\overline{\omega_{3}}\right)$ та частково визначає дрейф нуля $\omega_{0}$ і масштабного коефіцієнта $K$ КЛ. Через випадковий характер вказаних похибок усунути інструментальну похибку $\Delta \varphi_{I}$ ППСВК неможливо. Проте вона зменшується завдяки проведенню науково обгрунтованої кількості багаторазових вимірювань та фільтрації вихідного сигналу. Кількість багаторазових вимірювань науково обгрунтовується за відомою методикою, яка спрямована на визначення оптимальної (необхідної та достатньої) кількості вимірювань для досягнення заданої високої точності та достовірності результатів вимірювання, 3 огляду на часові та економічні аспекти витрат [12].

Запропонована математична модель похибки ППСВК використовується для алгоритмічної компенсації похибок вимірювання. Практична реалізація алгоритмічної компенсації похибок вимірювання ППСВК здійснюється у спеціалізованому програмному додатку ПК, що є складником ППСВК. Кінцевим результатом застосування запропонованої математичної моделі похибки ППСВК є підвищення точності гоніометричних вимірювань величин плоского кута.

Висновки. У статті наводиться повна математична модель похибки ППСВК, що враховує нестабільні несприятливі фактори (нестабільність швидкості обертання Землі навколо своєї осі, а також виникнення теплового та дробового ефектів у структурних елементах матриці), які з'являються в процесі функціонування ППСВК як у лабораторних, так і у виробничих умовах приладо- та машинобудування.

Запропонована повна математична модель похибки ППСВК $є$ основою алгоритмічної корекції результатів гоніометричних вимірювань, що виконується у спеціалізованому програмному додатку ПК безпосередньо в процесі експлуатації ППСВК та не потребує додаткового спеціалізованого лабораторного обладнання,

Використання пропонованої повної математичної моделі похибки ППСВК дає змогу підвищити точність гоніометричних вимірювань.

\section{Список літератури:}

1. Черепанська І.Ю., Безвесільна О.М., Сазонов А.Ю. Патент України на корисну модель 127373. Інтелектуальна система вимірювання кутів. МПК: G 01 В 21/22 (2006.01). Надр. 25.07.2018, Бюл. №14.

2. Безвесільна О.М. Алгоритмічні методи високоточного визначення лінійних прискорень. Вісник Хмельницького національного університету. 2018. № 5(265). С. 100-105.

3. Суханов С.В. Алгоритмы компенсации погрешностей выходного сигнала лазерного гороскопа. Вестник Нижсегородского университета им. И.Н. Лобачевского. 2011. № 3(2). С. 134-140. URL: https://cyberleninka.ru/ article/n/algoritmy-kompensatsii-pogreshnostey-vyhodnogo-signala-lazernogo-giroskopa (дата звернення 10.01.2019)

4. Ковшов Г.Н., Живцова Л.И. Математическая модель трехосевого микромеханического акселерометра для инклинометрической системы контроля и ориентации скважин. Вісник Придніпровської державної академії будівнищтва та архітектури. 2014. № 6. URL: https://cyberleninka.ru/article/v/matematicheskayamodel-trehosevogo-mikromehanicheskogo-akselerometra-dlya-inklinometricheskoy-sistemy-kontrolya-iorientatsii (дата звернення 10.01.2019).

5. Cherepanska I., Bezvesilna E., Sazonov A., Nechai S., Pidtychenko O. Development of artificial neural network for determining the components of errors when measuring angles using a goniometric software-hardware complex. Eastern-European journal of enterprise technologies. 2018. № 9 (95). P. 43-51.

6. Купер В.Я., Рубцов М.Г. Алгоритмические методы повышения точности измерений на основе обратных интерполяционных моделей. Вестник Самарского государственного технического универсиmema. 2010. № 3(28). С. 67-72.

7. Дорожкин А.Д., Джусь О.А. Анализ методов повышения точности и надежности данных о параметрах движения аэродинамического летательного аппарата. Современные проблемы науки и образования. 2014. № 3. URL: www.science-education.ru/ru/article/view?id=13610 (дата звернення 10.01.2019)

8. Павлов П.А. Анализ алгоритмов измерений лазерным динамическим гониометром. Измерительная техника. 2008. № 1. С. 17-20.

9. Ц Цибизова Т.Ю., Нгуен Д.Т. Алгоритмические способы коррекции навигационных систем в выходном сигнале. Интернет-журнал «Науковедение». 2015. № 3 (7). URL: http://naukovedenie.ru/PDF/162TVN315.pdf. DOI: $10.15862 / 162 \mathrm{TVN} 315$ (дата звернення 16.06.2020)

10. Черепанська I.Ю., Безвесільна О.М., Сазонов А.Ю. Алгоритмічна корекція результатів вимірювання прецизійної приладової гоніометричної системи. Вчені записки Таврійського наџіонального університету імені B.I. Вернадського Серія: Технічні науки. 2019. № 2. Том 30 (69). С. 6-11.

11. Безвесільна О.М. Автоматизований прецизійний пристрій для вимірювання кутів : Монографія. Житомир: ЖДТУ, 2010. 258 с.

12. Cherepanska I., Bezvesilna E., Sazonov A., Nechai S., Khylchenko T. The procedure for determining the number of measurements in the normalization of random error of an information-measuring system with elements of artificial intelligence. Eastern-European journal of enterprise technologies. 2017. № 5/9 (89). P. 58-67. 
Cherepanska I.Yu., Bezvesilna O.M., Sazonov A.Yu., Brodskyi Yu.B., Priadko V.A. MATHEMATICAL MODEL OF ERROR OF A PRECISION INSTRUMENTAL ANGLE MEASUREMENT SYSTEM

Complete mathematical of the precise instrument system of angles' measurement (PISAM) is shown in the paper. It is obtained by improving of well-known basic mathematical model of the error of goniometric system GS1L, which is the prototype PISAM. Complete mathematical model of the error of PISAM include instability of Earth rotation velocity regarding its axis and voltage fluctuations which occurred in CMOS as a part of PISAMdue to the presence of thermal and fractional effects that occur in its structural elements. Instability of the Earth's rotation velocity around its axis, as well as thermal and fractional effects that occur in the structural elements of the CMOS matrix are unfavorable factors that occur in both laboratory and industrial conditions, such as precision instrumentation and engineering and significantly reduce accuracy. In addition, the need to build a complete mathematical model of PISAM error is due to the synergistic integration in its structure of new technical means of automation-photosensitive CMOS-matrix and artificial neural networks (in the case of the latter in the form of neuroprocessors), as well as the use of a precision sensor which is sensitive to the instability of the Earth's speed. The proposed complete mathematical model of PISAM error is used to calculate the error values of goniometric measurements with the subsequent algorithmic correction of measurement results during the operation of PISAM. The advantages of the proposed complete mathematical model of PISAM error are that it systematically takes into account the features of PISAM components and allows further correction of measurement results in dynamic mode directly during the operation of PISAM without the use of specialized laboratory equipment. The practical implementation of this is carried out in a specialized software application, which is part of PISAM.

Key words: error, goniometric system, algorithmic correction, systematic error, random error, fluctuation voltages, fractional effect, thermal effect. 